\title{
Comparative study of suction drainage placement in cementless hip replacement among patients undergoing extended thromboprophylaxis: a prospective randomized study
}

\author{
Paweł Bartosz ${ }^{*}$ D, Wojciech Marczyński, Marcin Para, Maciej Kogut and Jerzy Białecki
}

\begin{abstract}
Background: The use of drains reportedly does not improve surgical outcomes after hip replacement. There is still a lack of strict recommendations for drain placement after primary hip replacement. This study aimed to assess the safety of not using suction drainage after primary hip replacement in a population of patients undergoing extended thromboprophylaxis.

Methods: In this prospective randomized study, all patients were qualified for primary hip replacement and were divided into two groups: with and without drainage. The inclusion criterion was idiopathic hip osteoarthritis. The exclusion criteria were secondary coxarthrosis, autoimmune disease, coagulopathy, venous/arterial thrombosis, hepatic/renal insufficiency, cement, or hybrid endoprostheses. We performed an intention-to-treat analysis. Clinical, laboratory, and radiographic parameters were measured for the first three days after surgery. Hematoma collection, due to extended thromboprophylaxis, in the joint and soft tissues was evaluated precisely. The patients underwent follow-up for 30 days.

Results: The final analysis included a total of 100 patients. We did not find any significant statistical differences between groups in terms of hip fluid collection ( 9.76 vs. $10.33 \mathrm{~mm}$, with and without drainage, respectively; mean difference, $0.6 \mathrm{~mm} ; 95 \%$ confidence interval [Cl] -2.8 to 3.9; $p=0.653$ ), estimated blood loss (1126 vs. $1224 \mathrm{ml}$; mean difference, $97.1 \mathrm{ml} ; 95 \% \mathrm{Cl}-84.1$ to 278.2; $p=0.59$ ), and hemoglobin levels on postoperative day 3 (11.05 vs. $10.85 \mathrm{~g} / \mathrm{dl}$; mean difference, $0.2 ; 95 \% \mathrm{Cl}-2.1$ to $2.5 ; p=0.53$ ). In addition, the other parameters did not show significant differences between groups. Notably, two cases of early infections were observed in the no-drainage group, whereas there were no such complications in the drainage group.

Conclusions: We conclude that the use of closed suction drainage after primary hip replacement is a safe procedure in patients undergoing extended thromboprophylaxis. Further research is warranted to validate these findings.
\end{abstract}

\footnotetext{
* Correspondence: pbartosz@vp.pl

Orthopedic Department, Centre of Postgraduate Medical Education,

Konarskiego 13, Kosciuszki 3/10B, 05-400 Otwock, Poland
}

C The Author(s). 2021 Open Access This article is licensed under a Creative Commons Attribution 4.0 International License, which permits use, sharing, adaptation, distribution and reproduction in any medium or format, as long as you give appropriate credit to the original author(s) and the source, provide a link to the Creative Commons licence, and indicate if changes were made. The images or other third party material in this article are included in the article's Creative Commons licence, unless indicated otherwise in a credit line to the material. If material is not included in the article's Creative Commons licence and your intended use is not permitted by statutory regulation or exceeds the permitted use, you will need to obtain permission directly from the copyright holder. To view a copy of this licence, visit http://creativecommons.org/licenses/by/4.0/. The Creative Commons Public Domain Dedication waiver (http://creativecommons.org/publicdomain/zero/1.0/) applies to the data made available in this article, unless otherwise stated in a credit line to the data. 
Trial registration: The study was successfully registered retrospectively at Clinicaltrial.gov with the identification number NCT04333264 03 April 2020.

Keywords: Suction drainage, Cementless hip replacement, Surgical outcomes, Hematoma

\section{Background}

Hip replacement surgery is one of the most effective procedures developed in the last century [1]. It is an orthopedic procedure that entails soft tissue and bone damage. Intraoperative blood loss can be limited by hemostasis at several stages and by using anatomical and non-aggressive surgical techniques. The use of fibrinolysis inhibitors such as tranexamic acid, as well as the topical use of vasoconstrictors, reduces both intra- and postoperative bleeding [2].

Significant intraoperative blood loss can affect hemostasis, leading to increased postoperative bleeding [3]. Suction drainage is used to drain blood from the hip joint. It is also used to assess bleeding activity, which may be an indication for urgent surgical intervention and repeated hemostasis. Excessive hematoma formation may also serve as a medium for bacterial growth. In this situation, not using suction drainage could lead to a larger hematoma in the joint and increase the risk of infection. Unfortunately, the drainage tube is also a significant portal of entry for infections in the hip. Several studies have documented the risk of infection in the context of prolonged suction drainage $[4,5]$. These factors encouraged us to perform an analysis to assess the risks of hematoma formation and infection among patients after primary hip replacement according to drainage use.

Postoperative blood loss is difficult to assess. The basic diagnostic method used was a physical examination supported by diagnostic imaging. Ultrasonography is the method of choice for assessing fluid collection in soft tissues [6].

According to the literature, proper use of thromboembolic prophylaxis, including low-molecular-weight heparin $(\mathrm{LMWH})$, may reduce the rate of postoperative hematomas [7]. In Poland, it is recommended that LMWH should be administered $12 \mathrm{~h}$ preoperatively and continued for 35 days after the intervention, which can be considered a form of extended thromboprophylaxis [8].

Until recently, strict recommendations for suction drainage after primary total hip replacement have not been available. Our study aimed to determine whether using a drain following hip replacement surgery results in similarities in joint hematoma formation, hemoglobin and C-reactive protein (CRP) levels, Visual Analog Scale (VAS), hip range of movement, wound exudation, soft tissue hematoma formation, perioperative bleeding, and blood transfusion administration when compared to not using a drain in patients undergoing extended perioperative thromboprophylaxis.

\section{Methods}

\section{Study design}

This study was planned and conducted using a prospective randomized design. We performed simple randomization using closed envelopes designating group allocation with an allocation ratio of 1:1. To detect our primary outcomes sample size of 50 patients per group will be sufficient to achieve a $5 \%$ significance level and a power of $80 \%$ according to Fagotti's study where VAS after surgery was $2 \pm 1.3$ for the no-drainage group and $1 \pm 0.2$ for the drainage group [9]. Information regarding drainage usage was enclosed in envelopes that were drawn by a person blinded to the study and randomized among the patients. Neither the patients nor the clinicians knew what procedures would be performed. The envelopes were opened in the operating theater at the end of surgery by the anesthesia team, just before the decision to leave suction drainage. If the surgeon, considering the course of the procedure and local conditions, decided that suction drainage was necessary despite randomization, the patient was excluded from the study and the envelope was not opened.

After recruitment, we evaluated the differences between the investigated groups in terms of age, sex, body weight, and blood clotting parameters to verify the randomization process. The study protocol was successfully retrospectively registered at Clinicaltrial.gov with the identification number NCT04333264 (03/04/2020).

\section{Participants and recruitment}

The inclusion criteria were primary hip osteoarthritis and age between 30 and 80 years. The exclusion criteria were secondary degenerative hip joint disease, autoimmune disease, congenital/secondary coagulopathy, history of venous/arterial thrombosis, hepatic/renal insufficiency, cement or hybrid endoprosthesis, and lack of patient consent.

Overall, 320 patients were successively operated on from March 14, 2016 to May 16, 2018, at the Orthopedic Department, Centre of Postgraduate Medical Education, Otwock, Poland. Only 134 patients met the inclusion criteria. All qualified patients signed written informed consent. The patients were allocated to two groups depending on the presence or absence of drains 
(Fig. 1); 100 patients qualified for the final analysis. Twenty patients withdrew their consent before the operation; 14 patients were excluded from the study due to intraoperative conditions (in 8 patients, the surgeon decided to leave drainage despite randomization; in $6 \mathrm{pa}$ tients, a cemented implant was needed due to intraoperative conditions). Thirty-four patients were excluded from the analysis despite fulfilling the eligibility criteria; however, none were excluded after the surgery or allocation process.

\section{Intervention}

The study protocol was approved by the relevant Bioethical Review Board. All methods used in this study were performed in accordance with approval from the Bioethical Committee of the Centre of Postgraduate Medical Education in Warsaw (approval number 13/PB/
2016). Written informed consent was obtained from all patients. The patients were prepared for surgery using a typical protocol. LMWH was administered for thromboprophylaxis in doses adjusted for body weight and risk factors. The first heparin dose was administered in the evening of the day before the surgery. Thromboprophylaxis was continued for 35 days after the surgery. All patients received intravenous tranexamic acid (Exacyl) at a dose of $15 \mathrm{mg}$ per kilogram of body weight, $10 \mathrm{~min}$ before skin incision. All the patients underwent spinal anesthesia. Experienced surgeons performed the surgeries using a posterolateral approach with cementless hip replacement implantation.

\section{Outcomes}

The primary outcomes measured were the size of the hip hematoma, hemoglobin level, CRP level, VAS, hip range of movement, wound exudation, soft tissue

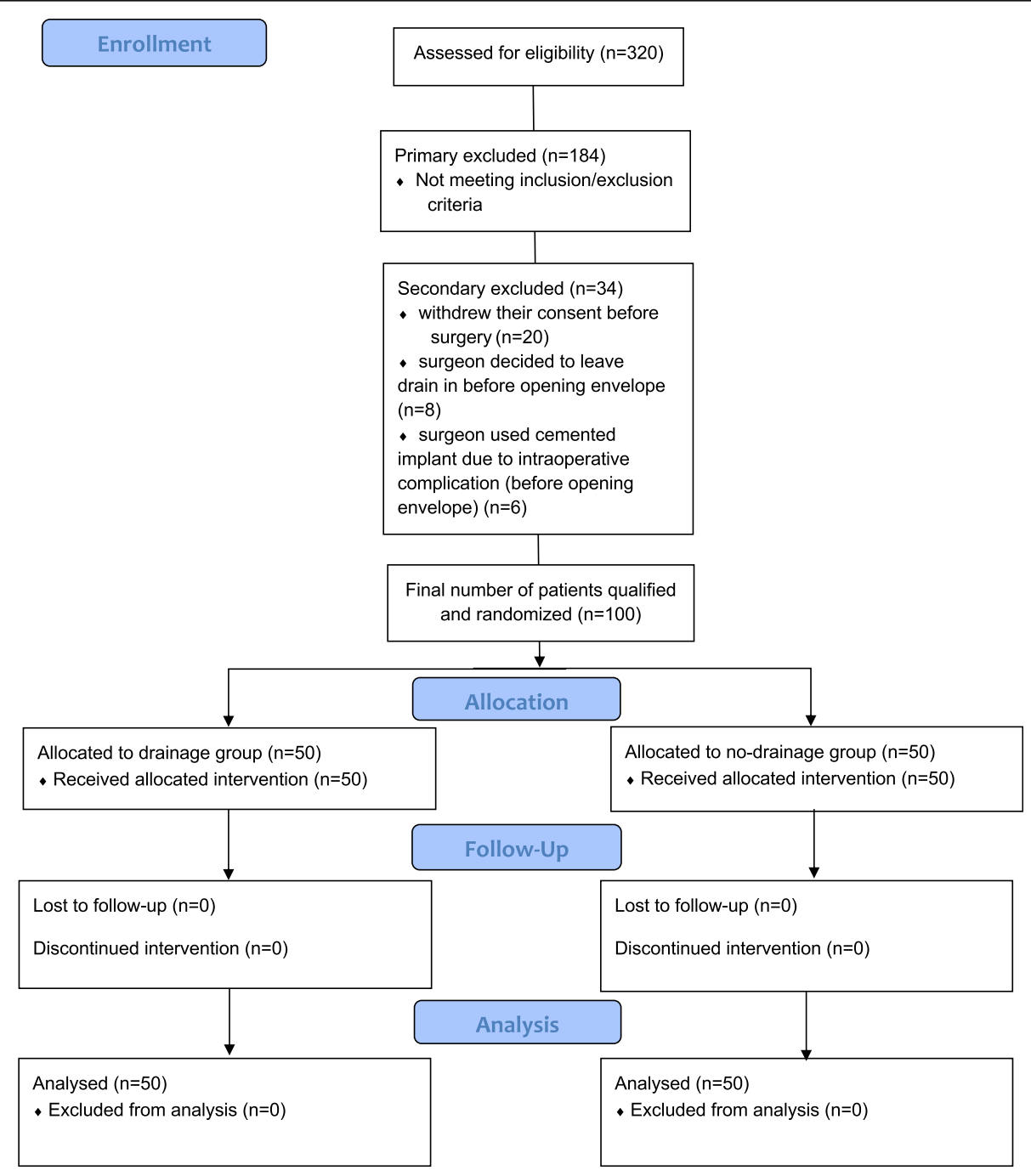

Fig. 1 Flowchart of patient allocation and randomization process 
hematoma, intraoperative bleeding, and blood transfusion. The secondary outcomes were infection, deep vein thrombosis, and readmission at 30 days after surgery. All data were collected by the three main investigators.

The volume of blood lost, along with occult bleeding, was calculated using the Gross formula:

$$
E B V x\left(H t_{(0)^{-}} H t_{(1)} / H t_{(a v)}\right),
$$

where $E B V$ represents the estimated patient's blood volume, $H t_{(0)}$ represents the preoperative hematocrit, $H t_{(1)}$ represents the hematocrit recorded $24 \mathrm{~h}$ after surgery, and $H t_{a v}$ represents the estimated pre- and postoperative hematocrit values. Despite limitations such as intraoperative fluid transfusion or renal insufficiency, the Gross formula is thought to credibly estimate intraoperative blood loss [10]. Blood loss was assessed and calculated on postoperative day 1 by an unblinded clinician.

Over the first $72 \mathrm{~h}$ after surgery, all patients underwent ultrasound scans of their hip joints and the postsurgical wound using an aseptic technique with a linear 3-9 MHz ultrasound transducer. The scans were performed with the patients in the supine position. The ultrasound scan assessed the fluid level at the level of the endoprosthesis neck in its long and transverse axes and detected fluid accumulation in the soft tissues around the incision area in its long and transverse axes. The exudate in the dressing was also noted on postoperative day 3 . All examinations were performed by a single clinician.

All laboratory tests of CRP and hemoglobin levels were completed on postoperative day 3 . Before surgery and within $72 \mathrm{~h}$ after surgery, the range of hip motion was assessed by an experienced clinician for flexion, abduction, adduction, and flexion contracture, and deviations in degrees were noted with a measurement accuracy of $5^{\circ}$. Pain levels were assessed using the VAS in all patients on postoperative day 3 , with scores ranging from 0 to 10 points. The patients were discharged depending on their general condition and progress in rehabilitation, usually between postoperative days 3 to 10 . Data regarding blood transfusions were collected at discharge. The follow-up period was 30 days, and all patients reached their final follow-up. Data regarding infections, deep vein thrombosis, and readmission were collected at the end of the follow-up period. We performed an intention-to-treat analysis.

\section{Data analysis}

Quantitative data were examined using Student's $t$-test, and their distributions were assessed using the ShapiroWilk test. Qualitative characteristics were assessed via contingency analysis using the chi-squared test with
Yates's correction or Fisher's F-tests, as appropriate. The statistical analyses were performed using SAS version 9.4 (SAS Institute Inc., Cary, NC, USA). Analysis items with $p<0.05$ were considered statistically significant.

\section{Results}

At the final follow-up, we assessed 100 patients: 50 in the drainage group and 50 in the no-drainage group. The statistical analysis did not reveal any statistically significant differences between the groups in terms of age, sex, body weight, degenerative disease severity on the Kellgren-Lawrence scale, and blood clotting factors (activated partial thromboplastin time [APTT], prothrombin time, and international normalized ratio) (Table 1).

The investigated patients included 55 women (55\%) and 45 men $(45 \%)$. The mean age of the patients was 62.8 years (range, 30-82), 64 years among women (range, 34-76), and 61.4 years among men (range, 30$82)$. The mean body mass index was $29 \mathrm{~kg} / \mathrm{m}^{2}$ (29.3 and $28.7 \mathrm{~kg} / \mathrm{m}^{2}$ in men and women, respectively).

\section{Primary outcomes}

The mean thickness of the fluid assessed at the level of the endoprosthesis neck in the drainage group was 10.3 $\mathrm{mm}$ while that in the no-drainage group was $9.8 \mathrm{~mm}$ (mean difference, $0.6 \mathrm{~mm}$; $95 \%$ confidence interval [CI] -2.9 to $3.8 ; p=0.653$ ).

The presence of hematomas in postoperative wound soft tissues, both suprafascial and subfascial, was assessed. Hematomas were detected in 7 patients in the no-drainage group and 8 patients in the drainage group $(p=0.78)$.

In both groups, hemoglobin and CRP values were measured preoperatively and 24 and $72 \mathrm{~h}$ postoperatively. At $72 \mathrm{~h}$ after surgery, there were no differences in hemoglobin values: 10.9 vs. $11.1 \mathrm{~g} / \mathrm{dl}$ for the drainage and no-drainage groups, respectively (mean difference, $0.2 \mathrm{~g} / \mathrm{dl} ; 95 \% \mathrm{CI}-2.1$ to $2.5 ; p=0.53$ ). The mean decreases in hemoglobin values before surgery and $72 \mathrm{~h}$ postoperatively between groups were not significant $(0.8$ vs. 0.8 in the no-drainage and drainage groups, respectively $(p=0.49)$. The CRP values measured $72 \mathrm{~h}$ postoperatively were also analyzed: 147.6 vs. $131 \mathrm{mg} / \mathrm{l}$ for the drainage and no-drainage groups, respectively (mean difference, $16.6 \mathrm{mg} / \mathrm{l} ; 95 \% \mathrm{CI}-11.3$ to 44.5 ). There were no statistically significant differences between the groups $(p=0.33)$.

The overall mean perioperative blood loss volume was $1175 \mathrm{ml}$ (range, 371-2384). The mean volume of blood loss was $1126 \mathrm{ml}$ in the no-drainage group and $1224 \mathrm{ml}$ in the drainage group (mean difference, $97.1 \mathrm{ml}$; $95 \% \mathrm{CI}$ -84.1 to $278.2 ; p=0.59$ ). Overall, blood transfusion was rarely needed, with a median of zero cases. In each 
Table 1 Distribution of basic parameters in both groups

\begin{tabular}{lllc}
\hline & Drainage mean (range) & No-drainage mean (range) & $\boldsymbol{p}$-value \\
\hline Age, years & $63.1(39-80)$ & $62.5(30-80)$ & 0.75 \\
Sex (M/F) & $24 / 26$ & $21 / 29$ & 0.69 \\
Body weight, kg & $83.5(52-124)$ & $81.7(56-110)$ & 0.54 \\
APTT, S & $26.5(16.1-37.2)$ & $26.4(18.1-40.8)$ & 0.93 \\
PT, S & $12.4(8.8-15.1)$ & $12.5(9.1-15.1)$ & 0.84 \\
INR & $1(0.8-1.3)$ & $1(0.8-1.3)$ & 0.89 \\
\hline
\end{tabular}

APTT activated partial thromboplastin time, INR international normalized ratio, M/F male/female, $P T$ prothrombin time

group, blood transfusion was necessary for five patients $(p=0.247)$.

The clinical status was assessed using the VAS to evaluate pain before surgery and $72 \mathrm{~h}$ after surgery. The median VAS scores before surgery were 6 and 7 points in the no-drainage and drainage groups, respectively (mean difference, $0.6 ; 95 \%$ CI -2 to 3.2). After surgery, the median VAS scores were 5 and 6 points in the nodrainage and drainage groups, respectively (mean difference, $0.4 ; 95 \%$ CI -2.3 to $3.1 ; p=0.71$ ) (Table 2).

The second clinical indicator evaluated was the hip range of motion $72 \mathrm{~h}$ after surgery. Due to varying severities of degenerative disease, we considered differences in the range of motion before surgery and $72 \mathrm{~h}$ after surgery. There were no significant differences in any of the movements tested between groups.

\section{Secondary outcomes}

There were no significant differences between the groups in terms of wound exudation on postoperative day $3(p=0.62)$. In the no-drainage group, early infection was observed in two patients. Infection was detected as a result of prolonged wound leakage (over 5 days) and was confirmed intraoperatively with two positive bacteriological cultures. These patients received the debridement, antibiotics, and implant retention (DAIR) procedure with good outcomes. There were no significant differences between the groups in the incidence of infection $(p=0.47)$.
The risk of deep vein thrombosis within 30 days after hip replacement surgery was also assessed. None of the patients in either group experienced postoperative deep vein thrombosis.

The mean hospitalization duration in both groups was 7 days; the mean difference between groups was 0.3 days (95\% CI -2.3 to $2.9 ; p=0.60$ ). Because of prolonged wound leakage, 2 patients were readmitted within the 30-day period after surgery and qualified for the DAIR procedure. These patients were diagnosed with early infection $(p=0.49)$ (Table 3).

\section{Discussion}

We assessed a homogenous group of patients who underwent hip replacement surgery. For legal reasons, all patients received extended thromboprophylaxis. The safety of suction drainage has not been evaluated in this group of patients. The parameter that might provide information about the impact of preoperative heparin dose was the amount of blood in the hip joint postoperatively. In our analysis, we checked fluid levels above the endoprosthesis neck using ultrasonography in the supine position. We found no differences in hip fluid levels between those who received suction drainage and those who did not ( 9.8 vs. $10.3 \mathrm{~mm}, p=0.653$ ). In addition, in comparing hematoma formation in soft tissue, intraoperative bleeding including occult bleeding, hemoglobin levels after surgery, and wound healing, we found no differences between the groups. Based on this, we concluded that refraining from placing suction drainage has

Table 2 Hip range of movement in both groups

\begin{tabular}{lcccc}
\hline & Drainage mean $(\mathbf{\pm S D})$ & No-drainage mean $(\mathbf{\pm S D})$ & $\boldsymbol{p}$-value & Mean difference $(\mathbf{9 5} \% \mathbf{C l})$ \\
\hline Flexion before surgery & $85.8(17.7)$ & $84(18.2)$ & 0.61 & $1.8(-5.4$ to 9) \\
Flexion on POD 3 & $74.9(12.9)$ & $78.5(13.3)$ & 0.5 & $3.6(-1.6$ to 8.8$)$ \\
Abduction before surgery & $20.7(9.3)$ & $18.4(12.2)$ & 0.23 & $2.3(-1.8$ to 6.4$)$ \\
Abduction on POD 3 & $19.8(7.9)$ & $19.3(8.3)$ & 0.54 & $0.5(-2.8$ to 3.8$)$ \\
Adduction before surgery & $9.7(8.4)$ & $9.1(8)$ & 0.61 & $0.6(-2.7$ to 3.9) \\
Adduction on POD 3 & $7.1(8.2)$ & $7.8(7.6)$ & 0.51 & $0.7(-2.5$ to 3.9) \\
Flexion contracture before surgery & $6.9(10.5)$ & $7.3(10.4)$ & 0.82 & $0.4(-3.8$ to 4.6) \\
Flexion contracture on POD 3 & $5(9.4)$ & $3.6(8.6)$ & 0.28 & $1.4(-2.2$ to 5) \\
\hline
\end{tabular}

Cl confidence interval, $P O D$ postoperative day, SD standard deviation 
Table 3 Primary and secondary outcomes in both groups

\begin{tabular}{|c|c|c|c|c|}
\hline & Drainage & No-drainage & $p$-value & Mean difference $(95 \% \mathrm{Cl})$ \\
\hline Hip hematoma size in USG Mean $( \pm S D)(m m)$ & $10.3(7.8)$ & $9.8(9)$ & 0.653 & $0.5(-2.8$ to 3.9$)$ \\
\hline Hb level on POD 3 Mean ( \pm SD) (mg/dl) & $10.9(5.7)$ & $11.1(5.6)$ & 0.53 & $0.2(-2.1$ to 2.5$)$ \\
\hline CRP level on POD 3 Mean ( \pm SD) (mg/l) & $131(63.6)$ & $147.6(75.2)$ & 0.33 & $16.6(-11.3$ to 44.5$)$ \\
\hline VAS on POD 3 Mean $( \pm S D)$ & $4.9(2.2)$ & $5.3(2.3)$ & 0.71 & $0.4(-2.3$ to 3.1$)$ \\
\hline Wound exudation on POD 3 (no.) & 9 & 11 & 0.62 & - \\
\hline Soft tissue hematoma on POD 3 (no.) & 8 & 7 & 0.78 & - \\
\hline Intraoperative bleeding Mean ( \pm SD) (ml) & $1224(438.2)$ & $1126(466.2)$ & 0.59 & $98(-84.1$ to 278.2$)$ \\
\hline Blood transfusion (no.) & 5 & 5 & 0.247 & - \\
\hline Infection (no.) & 0 & 2 & 0.47 & - \\
\hline Deep vein thrombosis (no.) & 0 & 0 & - & - \\
\hline Readmission within 30 days (no.) & 0 & 2 & 0.49 & - \\
\hline
\end{tabular}

$\mathrm{Cl}$ confidence interval, $C R P$ C-reactive protein, $\mathrm{Hb}$ hemoglobin, $P O D$ postoperative, SD standard deviation, USG ultrasonography, VAS Visual Analog Scale

no effect on patients receiving extended thromboembolic prophylaxis who undergo primary cementless hip replacement.

Due to the short observation period, the VAS and range of hip motion were used to assess patient-related outcomes. The VAS is commonly used to assess pain experienced by patients undergoing hip replacement surgery [11]. In a meta-analysis, Hou et al. did not demonstrate any differences in VAS scores between groups [12]. Fagotti et al. found significantly higher VAS scores among patients without suction drainage than among those with drainage [9]. In our study, $72 \mathrm{~h}$ postoperatively, a non-significant difference between the groups was identified in the VAS scores. Hip joint hematoma can reduce the range of motion [13]. Zeng et al. demonstrated a reduced range of hip joint mobility following surgery in patients among whom suction drainage was not placed [14]. Nevertheless, in a metaanalysis, Chen et al. did not find any differences in the range of motion between the drainage and no-drainage groups, as was confirmed in our study [15].

In the no-drainage group, we observed two patients with deep infections, whereas, in the drainage group, there were no infections. No surgical site infections (SSIs) were observed. Only two patients experienced prolonged wound leakage ( $>5$ days); however, in these cases, we recognized deep infections. We also did not find any significant differences in CRP levels. Historically, suction drainage was justified by the need to reduce hip joint hematoma and was consequently used to reduce the risk of periprosthetic infection [16]. The first papers to question the use of suction drainage were published in the $1990 \mathrm{~s}[17,18]$. Hou et al., based on 27 randomized studies, did not demonstrate a higher incidence of infections in patients without drainage [12]. Similar conclusions were drawn by Chen et al. based on 16 papers [15]. Although these studies showed findings similar to ours, Fagotti et al. reported two SSIs in the drainage group but no deep periprosthetic infections; in the no-drainage group, there were no SSIs, but one patient was diagnosed with deep infection. However, there were no significant differences between the groups [9]. In a study of 552 patients (577 hip joints), Walmsley et al. reported a higher incidence of SSIs ( $48 \%$ vs. $2.9 \%$ ) and deep infections $(0.7 \%$ vs. $0.4 \%)$ in the no-drainage group [19]. Zimmerli et al. questioned the diagnosis of SSI in patients with implants because it cannot be clinically differentiated from deep infections [20]. Despite the absence of statistically significant differences, this raised doubts about the non-use of suction drainage in patients undergoing extended thromboprophylaxis, which needs further evaluation.

We did not find an increased need for blood transfusions in either group. However, in a meta-analysis, Kelly et al. demonstrated that patients in the suction drainage group required blood transfusion significantly more frequently and had greater postoperative blood loss [21]. In another meta-analysis, Hou et al. also demonstrated significantly more frequent blood transfusions in the drainage group [12].

In most relevant publications, the majority of parameters did not differ significantly between groups [9, 19, $21,22]$. All these studies included heterogeneous groups: patients with primary and secondary osteoarthritis, coxarthrosis in the course of rheumatoid arthritis, and others. Some of these conditions can affect perioperative blood loss and the need for blood transfusion [23]. Despite this, because of Polish recommendations, some groups of patients undergoing extended thromboprophylaxis require longer heparin use due to risk factors for thrombosis. These patients could have achieved some benefits with the use of suction drainage. These conditions illustrate why further well-designed multicenter prospective studies are needed. 
This study had several limitations. First, it was a single-center study and therefore may be subject to selection bias. For this reason, we instituted strict inclusion and exclusion criteria. Therefore, multicenter studies are needed to validate our findings. A short observation period was appropriate for the intervention investigated. Therefore, we used proper scales to assess the short-term clinical outcomes. Many patients were excluded from the primary cohort, possibly influencing outcomes; however, all exclusions occurred before we opened the sealed envelopes, which ultimately did not significantly impact the randomization process. All therapists and assessors were blinded; however, at the point of ultrasonography examination and clinical evaluation (hip range of motion, VAS) on postoperative day 3, the use of suction drainage was visible, which could potentially have affected their assessment. Another limitation was the retrospective registration at ClinicalTrials.gov.

\section{Conclusions}

Hip replacement without suction drainage after surgery is a recognized therapeutic method. No superiority of either method was demonstrated in terms of the size of the hip hematoma, hemoglobin levels, CRP levels, VAS, hip range of movement, wound exudation, soft tissue hematoma, intraoperative bleeding, and blood transfusion. In light of these results, we recommend not routinely using suction drainage in patients undergoing extended thromboprophylaxis. Nevertheless, it is worth noting that there were two cases of early infection in the no-drainage group compared to none in the drainage group among patients who underwent hip replacement with extended thromboprophylaxis. This finding suggests the need for further research.

\section{Abbreviations}

APTT: Activated partial thromboplastin time; Cl: Confidence interval; CRP: Creactive protein; DAIR: Debridement, Antibiotics, Implant Retention procedure; LMWH: Low-molecular-weight heparin; SSIs: Surgical site infections; VAS: Visual analog scale

\section{Acknowledgements}

Not applicable.

\section{Authors' contributions \\ PB was involved in the study preparation, paper preparation, and data collection; WM was involved in the manuscript preparation and critical review; MP was involved in data collection and manuscript preparation; MK was involved in data collection and manuscript preparation; and JB was involved in both the critical review and study conception. All authors have reviewed and approved the final manuscript.}

\section{Funding}

Not applicable.

\section{Availability of data and materials}

The datasets used and/or analyzed during the current study are available from the corresponding author upon reasonable request.

\section{Declarations}

Ethics approval and consent to participate

The study protocol was approved by the Bioethical Review Board of the Center of Postgraduate Medical Education in Warsaw (approval number 13/ PB/2016). All participants signed written informed consent.

Consent for publication

Not applicable.

\section{Competing interests}

The authors declare that they have no competing interests.

Received: 30 September 2020 Accepted: 4 August 2021

Published online: 13 August 2021

\section{References}

1. Learmonth ID, Young C, Rorabec C. The operation of the century: total hip replacement. Lancet. 2007;370:1508-19.

2. Chen S, Wu K, Kong G, Feng W, Deng Z, Wang H. The efficacy of topical tranexamic acid in total hip arthroplasty: a meta-analysis. BMC Musculoskelet Disord. 2016;17:81.

3. Ghadimi K, Levy JH, Welsby IJ. Perioperative management of the bleeding patient. Br J Anaesth. 2016;117:iii18-30.

4. Saleh K, Olson M, Resig S, Bershadsky B, Kuskowski M, Gioe T, et al. Predictors of wound infection in hip and knee joint replacement: results from a 20-year surveillance program. J Orthop Res. 2002;20:506-15.

5. Lee GW, Park KS, Kim DY, Shin YR, Yoon TR. New strategy of closed suction drainage after primary total hip arthroplasty. Acta Orthop Traumatol Turc. 2017:51:223-6.

6. Białecki J, Bartosz P, Marczyński W, Zając J. Usefulness of ultrasonography in the diagnosis of hematoma after primary hip arthroplasty. J Ultrason. 2017; 17:149-53.

7. Mortazavi SM, Hansen P, Zmistowski B, Kane PW, Restrepo C, Parvizi J. Hematoma following primary total hip arthroplasty: a grave complication. J Arthroplasty. 2013;28:498-503.

8. Chmielewski D, Górecki A, Kusz D, Małdyk P, Marczyński W, Tomkowski W. [Principles of prevention of venous thromboembolism in orthopedics and traumatology (updated on 02/18/2014)]. Ortop Traumatol Rehabil. 2014;16: 227-39 (in Polish).

9. Fagotti L, Ejnisman L, Miyahara HS, Gurgel HMC, Croci AT, Vicente JRN. Use of closed suction drainage after primary total hip arthroplasty: a prospective randomized controlled trial. Rev Bras Ortop. 2018;53:236-43.

10. Gibon E, Courpied JP, Hamadouche M. Total joint replacement and blood loss: what is the best equation? Int Orthop. 2013;37:735-9.

11. Brismar BH, Hallert O, Tedhamre A, Lindgren JU. Early gain in pain reduction and hip function, but more complications following the direct anterior minimally invasive approach for total hip arthroplasty: a randomized trial of 100 patients with 5 years of follow up. Acta Orthop. 2018;89:484-9.

12. Hou N, Jing F, Rong W, He DW, Zhu JJ, Fang L, et al. [Meta analysis of the efficacy and safety of drainage after total hip arthroplasty]. Zhonghua Yi Xue Za Zhi. 2017;97:1668-72. (in Chinese).

13. Yumoto T, Joko R, Yamakawa Y, Yamada T, Naito H, Nakao A. Subperiosteal hematoma of the iliac bone: an unusual cause of acute hip pain after a fall. Am J Case Rep. 2018;19:1083-6.

14. Zeng WN, Zhou K, Zhou ZK, Shen B, Yang J, Kang PD, et al. Comparison between drainage and no-drainage after total hip replacement in Chinese subjects. Orthop Surg. 2014;6:28-32.

15. Chen $Z Y$, Gao $Y$, Chen W, Li X, Zhang YZ. Is wound drainage necessary in hip arthroplasty? A meta-analysis of randomized controlled trials. Eur J Orthop Surg Traumatol. 2014;24:939-46.

16. Waugh TR, Stinchfield FE. Suction drainage of orthopaedic wounds. J Bone Joint Surg Am. 1961;43-A:939-46.

17. Murphy JP, Scott JE. The effectiveness of suction drainage in total hip arthroplasty. J R Soc Med. 1993;86:388-9.

18. Hadden WA, McFarlane AG. A comparative study of closed-wound suction drainage vs. no drainage in total hip arthroplasty. J Arthroplasty. 1990;5; Suppl:21-4.

19. Walmsley PJ, Kelly MB, Hill RM, Brenkel I. A prospective, randomised, controlled trial of the use of drains in total hip arthroplasty. J Bone Joint Surg Br. 2005;87:1397-401. 
20. Zimmerli W. Clinical presentation and treatment of orthopaedic implantassociated infection. J Intern Med. 2014;276:111-9.

21. Kelly EG, Cashman JP, Imran FH, Conroy R, O'Byrne J. Systematic review and meta-analysis of closed suction drainage versus non-drainage in primary hip arthroplasty. Surg Technol Int. 2014;24:295-301.

22. Suarez JC, McNamara CA, Barksdale LC, Calvo C, Szubski CR, Patel PD.

Closed suction drainage has no benefits in anterior hip arthroplasty: a prospective, randomized trial. J Arthroplasty. 2016;31:1954-8.

23. Salt E, Wiggins AT, Rayens MK, Brown K, Eckmann K, Johannemann A, et al. Risk factors for transfusions following total joint arthroplasty in patients with rheumatoid arthritis. J Clin Rheumatol. 2018;24:422-6.

\section{Publisher's Note}

Springer Nature remains neutral with regard to jurisdictional claims in published maps and institutional affiliations.

Ready to submit your research? Choose BMC and benefit from:

- fast, convenient online submission

- thorough peer review by experienced researchers in your field

- rapid publication on acceptance

- support for research data, including large and complex data types

- gold Open Access which fosters wider collaboration and increased citations

- maximum visibility for your research: over $100 \mathrm{M}$ website views per year

At BMC, research is always in progress.

Learn more biomedcentral.com/submissions 